特別 講 演 3

\title{
Importance of integrated evaluation of the child with asthma
}

\author{
David Price \\ General Practice Airways Group Professor of Primary Care Respiratory Medicine \\ University of Aberdeen, Scotland
}

\section{Background:}

The control of adult asthma has improved immeasurably in recent years through use of regular anti-inflammatory therapy and additional long-acting controller therapy. However, outcomes in children have been slower to improve due in part to substantial variation in phenotypes of wheezing in children and different responses to asthma therapy. To achieve best outcomes in childhood asthma it is fundamental that these different patterns are recognised, that asthma control is properly assessed and appropriate therapy prescribed and taken.

\section{Current burden:}

Studies suggest that 1 in 7 children have symptoms justifying treatment for asthma and that asthma accounted for 14 per cent of all hospital admissions for childhood illnesses.

Of all children with asthma, the under-fives have the highest rates of hospital admission. Hospital treatment for asthma accounted for almost 60 per cent of all healthcare costs among pre-school children.

A recent study conducted via community pharmacies looked at continuing asthma symptoms in over 1200 children aged up to 14 years who were receiving prescription medicines for their asthma. It showed that despite a common perception that asthma was under control, 60 per cent had difficulty breathing at least once a month and for 37 per cent this occurred at least once a week. About $30 \%$ were woken at night by symptoms and about that many reported a dry cough and their ability to talk affected by asthma at least once weekly. Although 60 per cent used 'preventer' medication (cromoglycate or inhaled corticosteroids), on average children were using beta 2 agonist rescue medication almost three times a day. Recurring symptoms had a big impact on children's quality of life, restricting their abilities to do everything those without asthma could.

Possibly, given parents' persisting anxieties about the use of inhaled steroids by children, $42 \%$ of parents admitted to not taking inhaled steroids as recommended by their physicians.

\section{Early childhood patterns of disease and effect of inhaled steroids:}

Children's wheezing is predominantly intermittent and tends to be related to viral infections or to be exercise-induced. In fact, epidemiologic studies suggest that upper respiratory tract infections (URTIs) have played a role in about 80 - 85 per cent of wheezing episodes in children. In these circumstances inhaled corticosteroids have limited efficacy and even oral steroids have been shown to have virtually no benefit. 
This is in contrast to studies in persistent wheezing which do suggest benefit from using inhaled steroids.

Asthma in childhood is less easily diagnosed than in adults. Many children may not be prescribed maintenance preventive therapy until they have suffered several repeat episodes in close succession. For pre-school children with episodic wheeze where symptoms may not occur for months at a time, regular inhaled corticosteroids do not appear to be wholly effective. This appears to be due to a number of factors.

Firstly, children have a less effective inhaler technique than adults with less powerful inspiratory flow and are more likely to have trouble co-ordinating inspiration with activation of some inhalers. Very small children require spacers and masks which can further complicate asthma treatment.

Secondly, wheezing associated with viral infections appears to be associated with leukotriene production and it is now clear that inhaled steroids poorly suppress leukotriene production.

\section{Role of Leukotriene Antagonists in Childhood Asthma:}

Leukotriene antagonists appear to be a useful preventive asthma strategy in children from 6 months of age upwards. Clinical evidence suggests that these drugs show clinical benefit within the first 24 hours after they are administered and for a variety of patterns of childhood wheezing.

A recent double-blind randomised study examined the effects of a short course of montelukast therapy on children's asthma and their subsequent use of medical services, whether hospital specialists, accident and emergency staff or the patient's local GP.

Just over 200 children aged 2 to 14 were randomised to either montelukast (4mg or $5 \mathrm{mg}$ dependent on age) or placebo to be started as soon as the next episode of wheeziness started or at the first sign of an upper respiratory tract infection when this was the usual trigger for asthma symptoms. Children in the montelukast group used nearly $50 \%$ less healthcare resources than the placebo-treated group. Another study using regular montelukast to treat intermittent asthma showed reductions in exacerbations of asthma using montelukast.

\section{Conclusions:}

Wheezing illness produces major burden for young children. It is essential to fully assess the pattern of this wheezing as much will not respond well to traditional anti-inflammatory therapy using inhaled steroids apart from those with patterns of persistent wheezing. Leukotriene antagonists appear to be effective in the broad patterns of childhood wheezing.

\section{References}

${ }^{1}$ Johnston SL, Pattemore PK, Sanderson G et al. Community study of role of viral infections in exacerbations of asthma in 9-11 year old children. Brit Med J 1995; 310: 1225-9.

${ }^{2}$ Rakes GP. Arruda E, Ingram JM et al. Rhinovirus and respiratory syncytial virus in wheezing children requiring emergency care. IgE and eosinophil analyses. Am J Respir Crit Care Med 1999; 159: 785-90 ${ }^{3}$ Doull IJ, Lampe FC, Smith S et al. Effect of inhaled corticosteroids on episodes of wheezing associated with viral wheeze in pre-school children. Brit MedJ 1997; 315: 858-62. 
${ }^{4}$ Oommen A, Lambert P, Grigg J. Efficacy of a short course of patient initiated oral prednisolone for viral wheeze in children aged 1-5 years: randomised controlled trial. Lancet 2003;362:1433-1438

${ }^{5}$ Wilson N, Sloper K, Silverman M. Effect of continuous treatment with topical corticoseroid on episodic viral wheeze in pre-school children. Arch Dis Child 1995; 72: 317-20.

${ }^{6} \mathrm{Knorr} \mathrm{B}$, Frabchi LM et al. Montelukast, a leukotriene receptor antagonist for the treatment of persistent asthma in children aged 2 to 5 . Pediatrics 2001; 108: E48.

${ }^{7}$ Summary of product characteristics. Singulair granules, MSD 2004.

${ }^{8}$ Robertson C F, Henry R L, Mellis C, Fitzgerald D, Glasgow N, Zheng X,

Turner J, Sant M and Price D Short course montelukast for intermittent asthma in children: the Pre-Empt Study. Presented at the American Thoracic Society Conference May 21-26, 2004, Orlando, Florida. Abstract A53, Poster C71 Montelukast.

${ }^{9}$ Bisgaard H, Zielen S, Garcia-Garcia ML, Johnston SL, Gilles L, Menten J, Tozzi CA, Polos P. Montelukast reduces asthma exacerbations in 2- to 5-year-old children with intermittent asthma. Am J Respir Crit Care Med. 2005; 171:315-22 